DOI: $10.38136 /$ jgon. 778713

\title{
Çok Düşük Doğum Ağırlıkıı Prematüre Yenidoğanlarda Pulmoner Kanama Sıklığı ve Risk Faktörleri
}

\section{The Frequency of Pulmonary Hemorrhage and Associated Risk Factors in Very Low Birth Weight Premature Newborns}

\author{
Özlem BOZKURT \\ Ebru Yücesoy BAĞDiKEN 2 \\ Ayșe İrem ZÖHRE \\ Deniz AKÇA ${ }^{3}$
}

(1) Orcid ID:0000-0002-1282-9030
(1) Orcid ID:0000-0002-7404-2962
(1) Orcid ID:0000-0001-8557-3833
(1) Orcid ID:0000-0002-7987-3917

${ }^{1}$ Demiroğlu Bilim Üniversitesi, Çocuk Sağlığı ve Hastalıkları, Neonatoloji Bilim Dalı, İstanbul, Türkiye

2 Șanlıurfa Eğitim Araștırma Hastanesi, Yenidoğan Kliniği, Șanlıurfa, Türkiye

${ }^{3}$ Șanlıurfa Eğitim Araștırma Hastanesi, Pediatri, Șanlıurfa, Türkiye

\section{öz}

Amaç: Pulmoner kanama prematüre bebeklerde önemli bir mortalite nedenidir. Bu çalışmada çok düşük doğum ağırıklı prematüre bebeklerde pulmoner kanama sıkığı ve pulmoner kanama ilişkili risk faktörlerinin belirlenmesi amaçlanmıştır.

Gereçler ve Yöntem: Şanlıurfa Eğitim Araştırma Hastanesi Yenidoğan Yoğun Bakım Ünitesi'ne Eylül 2017 ve Şubat 2019 tarihleri arasında yatırılan doğum ağırlığı $\leq 1500$ gram, gestasyon haftası $\leq 32$ hafta olan prematüre bebekler retrospektif olarak çalışmaya alındı. Pulmoner kanama gelişen bebeklerin özellikleri ve risk faktörleri kontrol grubuyla karşılaştırıldı.

Bulgular: İki yüz doksan sekiz çok düşük doğum ağırlıklı prematüre bebek çalışmaya dahil edildi. Hastaların \%20,8'inde pulmoner kanama gelişti. Pulmoner kanama gelişen grupta ortalama gestasyon haftası $(26,5$ $\pm 1,9)$ ve doğum ağılığı $(892 \pm 269)$ anlamlı olarak düşüktü $(p<0,001)$. Doğum ağırlığı (OO = 0,99 [\%95 GA = 0,99-0,99]; $p=0,037)$, antenatal steroid uygulanmamış olması (OO = 3,26 [\%95 GA = 1,246-8,54]; $p=$ $0,016)$ ve doğum salonunda entübasyon varlığı $(\mathrm{OO}=5,32[\% 95 \mathrm{GA}=$ $1,694-16,72] ; p=0,004$ ) pulmoner kanama açısından anlamlı risk faktörleri olarak saptandı.

Sonuç: Doğum ağırlığının düşüklüğü, antenatal steroid uygulanmamas ve doğum salonunda entübasyon gereksinimi pulmoner kanama riskini artırmaktadır. Antenatal bakımı iyileştirmek pulmoner kanama sıklığını azaltabilir.

Anahtar kelimeler: prematürite, yenidoğan, pulmoner kanama

\section{GíRiş}

Pulmoner kanama, endotrakeal tüp ya da trakeada taze kan bulunması ve eşlik eden ani klinik bozulma olması olarak tanımlanmaktadır (1). Term bebeklerde de görülmekle birlikte özellikle doğum ağırlığı $\leq 1500$ gram olan çok düşük doğum ağırlıkı (ÇDDA) prematürelerde ve intrauterin büyüme kısıtıılığı

Sorumlu Yazar/ Corresponding Author:

Özlem Bozkurt

Demiroğlu Bilim Üniversitesi, Çocuk Sağlığı ve Hastalıkları, Neonatoloji Bilim Dalı, İstanbul Büyükdere Caddesi, No:120/34394 Esentepe Şişli/listanbul, Türkiye E-mail: : dr_kalyoncu@hotmail.com

\section{ABSTRACT}

Aim: Pulmonary hemorrhage is an important reason for mortality in premature infants. In this study we aimed to evaluate the frequency of pulmonary hemorrhage and associated risk factors in very low birth weight premature infants.

Materials and Method: Premature infants with birth weight $\leq 1500 \mathrm{~g}$ and gestational age $\leq 32$ weeks admitted to Sanliurfa Training and Research Hospital Neonatal Intensive Care Unit between September 2017 and February 2019 were included retrospectively in the study. The characteristics and risk factors of infants with pulmonary hemorrhage were compared with the control group.

Results: Two hundred and ninety eight infants were included in the study. Pulmonary hemorrhage developed in $20.8 \%$ of patients. Mean gestational age $(26.5 \pm 1.9)$ and birth weight $(892 \pm 269)$ were significantly lower in pulmonary hemorrhage group ( $p<0.001)$. Birth weight (OR $=0.99[\% 95 \mathrm{Cl}=0.99-0.99] ; p=0.037$ ), lack of antenatal steroid therapy $(\mathrm{OR}=3.26[\% 95 \mathrm{Cl}=1.246-8.54] ; p=0.016)$ and intubation in delivery room $(O R=5.32[\% 95 \mathrm{Cl}=1.694-16.72] ; p=0.004)$ were significant risk factors for development of pulmonary hemorrhage.

Conclusion: Lower birth weight, lack of antenatal steroid therapy and intubation in delivery room increase the risk of pulmonary hemorrhage. Improving antenatal care may reduce pulmonary hemorrhage.

Key words: prematurity, newborn, pulmonary hemorrhage

bulunan bebeklerde gelişmektedir (2). ÇDDA'lı bebeklerde \%3-12 arasında değişen sıklıklarda bildirilmiştir (3-5). Düşük gestasyon yaşı, düşük doğum ağırığı, erkek cinsiyet, respiratuvar distres sendromu (RDS), surfaktan uygulaması, patent duktus arteriozus (PDA), sepsis, hipoksi, ağır hipotermi ve konjenital kalp hastalığı gibi birçok durum ile ilişkilidir $(1,2,6,7)$. Pulmoner kanamada mortalite $\% 75^{\prime}$ lerin üstüne çıkan oranlarda bildirilmekte ve ölümlerin çoğunluğu ilk 72 saat içinde gerçekleşmektedir $(4,6)$.

Başvuru tarihi : 14.08.2020 Kabul tarihi : 17.09 .2020 
Ülkemizde neonatal mortalitenin en yüksek olduğu illerden biri Şanlıurfa'dır ve prematürite önde gelen neonatal ölüm nedeni olarak bildirilmiştir (8). Prematüre bebeklerde mortalitenin önde gelen nedenlerinden biri pulmoner kanamadır $(6,8)$.

Bu çalışmada Şanlıurfa Eğitim Araştırma Hastanesi Yenidoğan Yoğun Bakım Ünitesi'ne (YYBÜ) yatan ÇDDA'lı prematüre bebeklerde pulmoner kanama sıklığının ve pulmoner kanama ile ilişkili risk faktörlerinin belirlenmesi amaçlanmıştır.

\section{GEREÇLER VE YÖNTEM}

Şanlıurfa Eğitim Araştırma Hastanesi YYBÜ'ne Eylül 2017 ve Şubat 2019 tarihleri arasında yatırılan doğum ağırlığı $\leq 1500$ gram, gestasyon haftası $\leq 32$ hafta olan prematüre bebekler çalışmaya alındı. Major konjenital/kromozomal anomalisi olan ve dış merkezde doğan hastalar çalışma dışı bırakıldı. Veriler retrospektif olarak hasta dosyaları ve otomasyon sisteminden elde edildi. Pulmoner kanama, endotrakeal tüpte taze kırmızı kan olmasıyla birlikte solunumsal parametrelerde ani kötüleşme; $\mathrm{FiO} 2$ değerinde $\geq 0,1$ artış, tepe inspiratuar basınç (PiP) değerinde $\geq \% 10$ artış, pozitif ekspiryum sonu basınç (PEEP) değerinde herhangi bir artış ihtiyacı ya da yüksek frekanslı osilatuar ventilasyona (HFO) geçiş gereksinimi olarak tanımlandı. Pulmoner kanama gelişmeyen hastalar kontrol grubu olarak analiz edildi. Antenatal öykü, maternal yaş, doğum şekli, doğum salonunda entübasyon intiyacı, 5. dakika Apgar skoru, başvuru hastalık şiddet skoru (Clinical Risk Index for Babies-CRiB II) (9), antenatal steroid tedavisi, surfaktan kullanımı, pulmoner kanama zamanı, hemodinamik anlamlı PDA, ağır intraventriküler kanama (IVK), erken sepsis ve mortalite kaydedildi.

Anneye doğumdan önce 24 saat arayla iki doz betametazon uygulanmışsa antenatal steroid tedavisi uygulanmış olarak kabul edildi.

Papile sınıflamasına (10) göre evre 3 ve 4 kanamalar ağır IVK olarak kaydedildi.

Hemodinamik anlamlı PDA tanısı çocuk kardiyoloji uzamanı tarafından ekokardiyografik olarak konuldu.

Çalışma için Harran Üniversitesi etik komitesinden izin alındı. Etik Kurul No: 29.06.2020-HRU/20.12.24

\section{İstatistiksel Analiz}

Kategorik değişkenler sayı ve yüzde olarak, devamlı değişkenler ortalama \pm standart sapma (SD) ve ortanca (minimum-maksimum) olarak ifade edildi. Devamlı değişkenlerin analizi için Student t-testi ve Mann-Whitney U testi kullanıldı. Kategorik değişkenlerin karşılaştırımasında X2 testi ve Fischer exact test kullanıldı. Tüm veriler pulmoner kanama olan ve olmayan grup için analiz edildi. Tek değişkenli analizde anlamlı olan değişkenlerde çoklu doğrusal bağıntıyı araştırmak için varyans artış faktörü (variance inflation factors-VIF) değerleri hesaplandı. VIF değeri 2'nin altında bulunan değişkenler çok değişkenli lojistik regresyon analizine dahil edildi. Tüm istatistiksel analizler SPSS 24.0 (SPSS, Chicago, IL, USA) ile yapıldı. P <0,05 istatistiksel olarak anlamlı kabul edildi.

\section{BULGULAR}

On sekiz aylık çalışma süresince 316 ÇDDA'lı prematüre bebek YYBÜ'nde izlendi. Major konjenital/kromozomal anomalisi olan 10 bebek ve dış merkezde doğan 8 bebek çalışma dışı bırakııdı. Toplam 298 ÇDDA'lı bebek çalışmaya dahil edildi. Pulmoner kanama 62 bebekte $(\% 20,8)$ gözlendi. Ortanca pulmoner kanama gelişme zamanı postnatal 40. (12-72) saatti.
Pulmoner kanama ve kontrol grubunun demografik ve klinik özellikleri Tablo 1 'de özetlenmiştir.

Tablo 1. Hastaların demografik ve klinik özellikleri

\begin{tabular}{lccc}
\hline & Pulmoner kanama & Kontrol & $\mathrm{p}$ \\
& $\mathrm{n}=62$ & $\mathrm{n}=236$ & \\
\hline Gebelik haftası, hafta & $26,5 \pm 1,9$ & $27,9 \pm 2,9$ & $<0,001$ \\
Doğum ağırlığı, gr & $892 \pm 269$ & $1056 \pm 327$ & $<0,001$ \\
Erkek cinsiyet, $\mathrm{n}(\%)$ & $32(51,6)$ & $116(49,2)$ & 0,73 \\
Sezaryen ile doğum, n (\%) & $47(75,8)$ & $156(66,1)$ & 0,14 \\
Anne yaş1 & $26,5 \pm 6,7$ & $28,3 \pm 6,6$ & 0,07 \\
5. dakika Apgar skoru & $6(2-8)$ & $7(3-9)$ & $<0,001$ \\
Doğum salonunda entübas- & $58(93,5)$ & $138(58,5)$ & $<0,001$ \\
yon, n (\%) & & & \\
CRỉ skoru & $13(3-20)$ & $6(0-20)$ & $<0,001$ \\
IUBG, n (\%) & $5(8,1)$ & $19(8,1)$ & 0,79 \\
Preeklampsi, n (\%) & $19(30,6)$ & $85(36)$ & 0,43 \\
Oligohidramniyos, n (\%) & $4(6,5)$ & $17(7,2)$ & 0,83 \\
Koryoamniyonit, $\mathrm{n}(\%)$ & $16(25,8)$ & $30(12,7)$ & 0,01 \\
Çoğul gebelik, n (\%) & $15(24,2)$ & $50(21,2)$ & 0,61 \\
Suriyeli mülteci, $\mathrm{n}(\%)$ & $22(35,5)$ & $77(32,6)$ & 0,13 \\
Antenatal steroid, $\mathrm{n}(\%)$ & $7(11,3)$ & $85(36)$ & $<0,001$ \\
RDS, n (\%) & $62(100)$ & $197(83,5)$ & 0,001 \\
Surfaktan tedavisi, n (\%) & $62(100)$ & $174(73,7)$ & $<0,001$ \\
Erken sepsis, n (\%) & $6(9,7)$ & $14(6,4)$ & 0,4 \\
PDA, n (\%) & $24(38,7)$ & $64(27,1)$ & 0,03 \\
Grade 3-4 IVK, n (\%) & $14(22,6)$ & $18(7,6)$ & $<0,001$ \\
Mortalite, n (\%) & $56(90,3)$ & $66(28)$ & $<0,001$ \\
\hline
\end{tabular}

CRIB: Clinical risk index for babies, IUBG: Intrauterin büyüme geriliği, IVK: İntraventriküler kanama, PDA: Patent duktus arteriozus, RDS: respiratuvar distres sendromu

Ortalama gestasyon yaşı $(26,5 \pm 1,9$ ve $27,9 \pm 2,9$ hafta; $p<0,001)$ ve doğum ağılığı $(892 \pm 269$ ve $1056 \pm 327$ gr; $p<0,001)$ pulmoner kanama gelişen grupta kontrol grubuna göre anlamlı olarak düşük bulundu. Pulmoner kanama gelişen hastaların 42'sinin $(\% 67,7)$ doğum ağırığı 1000 gram altındaydı. Antenatal faktörler değerlendirildiğinde, pulmoner kanama grubunda antenatal steroid uygulama oranı $(\% 11,3$ ve $\% 36, p<0,001)$ kontrol grubuna göre anlamlı olarak düşük, maternal koryoamniyonit sıklığı $(\% 25,8$ ve $\% 12,7, p=0,01)$ ise anlamlı olarak yüksek saptandı. Pulmoner kanama gelişen grupta 5. dakika Apgar skorları (6 (2-8) ve $7(3-9), p<0,001)$ anlamlı olarak düşük ve CRIB skorları (13 (3-20) ve $6(0-20), p<0,001)$ anlamlı olarak daha yüksekti. Doğum salonunda entübasyon gereksinimi pulmoner kanama grubunda anlamlı olarak daha sık saptandı $(p<0,001)$.

Pulmoner kanama gelişen bebeklerin tamamı RDS tanısı almıştı ve mekanik ventilatörde izlenmekteydi. Hemodinamik anlamlı PDA sıklığı pulmoner kanama grubunda anlamlı olarak yüksek saptandı (\%38,7 ve $\% 27,1, p=0,03)$.

Mortalite pulmoner kanama grubunda kontrol grubuna göre anlamlı olarak yüksekti $(\% 90,3$ ve $\% 28, p<0,001)$.

Çok değişkenli lojistik regresyon analizinde doğum ağırığı (OO = 0,99 [\%95 $\mathrm{GA}=0,99-0,99] ; p=0,037)$, antenatal steroid uygulanmamış olması $(00=$ $3,26[\% 95 \mathrm{GA}=1,246-8,54] ; p=0,016)$ ve doğum salonunda entübasyon varlığı $(O O=5,32[\% 95 \mathrm{GA}=1,694-16,72] ; p=0,004)$ pulmoner kanama ile ilişkili bağımsız risk faktörleri olarak saptandı (Tablo 2). 
Tablo 2. Pulmoner Kanama ile ilişkili risk faktörleri

\begin{tabular}{lccc}
\hline & $\mathrm{OO}$ & $\% 95 \mathrm{GA}$ & $\mathrm{p}$ \\
\hline Doğum ağırlı̆̆ & 0,99 & $0,99-0,99$ & 0,037 \\
Anne yaşı & 0.97 & $0,924-1,02$ & 0,267 \\
Hemodinamik anlamlı PDA & 1,1 & $0,57-2,14$ & 0,765 \\
Mülteci olma & 1,18 & $0,584-2,38$ & 0,644 \\
Antenatal steroid uygulan- & 3,26 & $1,246-8,54$ & 0,016 \\
maması & & & \\
Koryoamniyonit & 1,72 & $0,763-3,87$ & 0,191 \\
Doğum salonunda entübasyon & 5,32 & $1,694-16,72$ & 0,004 \\
gereksinimi & & & \\
\hline
\end{tabular}

GA: Güven aralığı (Confidence interval), OO: Odds Oranı (Odds Ratio), PDA: Patent duktus arteriozus

\section{TARTIŞMA}

Çalışmamızda pulmoner kanama sıklığı \%20,5 olarak gözlendi. Antenatal steroid uygulanmaması, doğum salonunda entübasyon gereksinimi ve doğum ağırlığının düşüklüğü pulmoner kanama ile ilişkili risk faktörleri olarak saptandı.

Pulmoner kanama çoğunlukla ağır RDS'li prematüre bebeklerde gelişmektedir. ÇDDA'lı prematürelerde insidansı \%3,2-13 arasında değişmektedir (3-5). Ülkemizde son yıllarda yapılmış olan tek çalışmada aşırı preterm bebeklerde pulmoner kanama sıklığı \%13,5 olarak rapor edilmiştir (11). Ferreira ve ark.'nın (4) çalışmasında pulmoner kanama gelişen bebeklerin \%90'ını ÇDDA'lı bebekler oluşturmuştur. Çalışmamızda pulmoner kanama gelişen hastaların \%67,7'si 1000 gram altındaydı. Pulmoner kanamanın patogenezi tam olarak aydınlatılamamakla birlikte esasen prematürite ve ilişkili durumlara bağlı olduğu açıktır. Pulmoner vasküler rezistansın düşmesiyle birlikte soldan sağa şant, sol ventrikül yetmezliği ve pulmoner akımın artması, kapiller duvarda transmural basınç artışı, alveol yüzeyindeki gerilim öne sürülen patofizyolojik mekanizmalar arasındadır $(1,12)$.

Ren Xia Ling ve ark. (13) vakaların \%85'inde pulmoner kanamanın ilk 3 gün içinde geliştiğini rapor etmiştir. Çalışmamızda median kanama zamanı postnatal 40. saat olarak saptandı. Berger ve ark. (2) median 46. saatte, Tomaszewska ve ark. (6) ise çalışmamıza benzer şekilde median 40. saatte kanama gözlemlemişlerdir. Bu kadar erken dönemde gözlenen kanama antenatal ve perinatal döneme ait faktörlere işaret edebilir. Doğum salonunda pozitif basınçlı ventilasyon, doğum salonunda entübasyon gereksinimi ve düşük Apgar skorları pulmoner kanama ile ilişkili risk faktörleri olarak saptanmıştır (2, 4, 14). Çalışmamızda doğum salonunda entübasyon gereksinimi pulmoner kanama riskini 5,3 kat artırdı ve bu ilişki çok değişkenli lojistik regresyon analizinde de devam etti. Doğum salonunda canlandırma intiyacı da patofizyolojide antenatal ve natal faktörlerin etkin olduğunun göstergesi olabilir.

Berger ve ark. (2) antenatal glukokortikoid tedavisinin özellikle 24-26 gebelik haftasındaki gebelere uygulandığında pulmoner kanama riskini anlamlı ölçüde azaltığını saptamışlardır. Antenatal steroidlerin surfaktan üretimini uyararak ve kapiller geçirgenliği azaltarak damar yatağında oluşturduğu yapısal ve biyokimyasal değişimin pulmoner kapiller ağı pulmoner kanamaya daha az yatkın hale getirdiği düşünülmektedir. Çalışmamızda Berger ve ark.'na benzer şekilde antenatal steroid uygulanmaması pulmoner kanama riskini anlamIı olarak artırmıştır. Antenatal steroid ve pulmoner kanama ilişkisi Ferreira ve ark.'nın (4) çalışmasında gösterilememiştir. Ülkemizden Özalkaya ve ark.'nın (11) çalışmasında da benzer ilişki saptanmamıştır.

Prenatal inflamasyonun akciğer gelişimini hızlandırdığı düşünülmektedir. Yapılan meta-analizlerde maternal koryoamniyonitin akciğer olgunlaşmasını artırarak RDS sıkı̆̆ını azalttığı saptanmıştır (15). Buna karşın koryoamniyonitin fetal akciğerde inflamatuar süreci uyararak pulmoner kanamaya yat- kınlık sağlayabileceği de düşünülmektedir. Çalışmamızda pulmoner kanama gelişen grupta maternal koryoamniyonit anlamlı olarak yüksek saptanmıştır. Ancak bu ilişki çok değişkenli lojistik regresyon analizinde gösterilememiştir.

PDA'nın pulmoner kanamadaki rolü net olarak kanıtlanamamıştır. Kluckow ve Evans (16) pulmoner kanama gelişen yenidoğanlarda kanama öncesi PDA ve pulmoner kan akımında artış olduğunu saptamışlardır. PDA'nın soldan sağa şantı artırarak pulmoner basınç artışına, kapiller duvarında zedelenme ve geçirgenlik artışına yol açarak pulmoner kanamayı artırdığı belirtilmiştir (17). Alfaleh ve ark. (18) profilaktik indometazinin PDA'yı kapatarak ilk birkaç gün içinde pulmoner kanamayı azalttığını saptamışlardır. Bazı çalışmalarda ise PDA ve pulmoner kanama ilişkisi gösterilememiştir $(2,4)$. Çalışmamızda pulmoner kanama gelişme zamanı ortanca olarak postnatal 40. saattir. Bu süre ve öncesinde pulmoner kanama gelişen hastalarda henüz PDA'ya yönelik ekokardiyografik inceleme yapılamamış olduğundan PDA'nın pulmoner kanama üzerine net etkisini bilebilmek tam olarak mümkün gözükmemektedir.

Pulmoner kanama, klinik durumda ani kötüleşme, hipotansiyon, perfüzyon bozukluğu, serebral kan akımında dalgalanmalar, hipoksi ve son olarak da intraventriküler kanamaya neden olabilir. Çalışmamızda pulmoner kanama grubunda daha sık olarak ağır IVK görüldü. Literatürde belirtildiği gibi pulmoner kanama sırasında gerçekleşen ani hemodinamik değişikliklere bağlı olarak pulmoner kanama sırasında ya da hemen sonrasında ağır IVK gelişmektedir (14).

Pulmoner kanama etkin bir tedavisi olmayan ve oldukça yüksek mortaliteyle seyreden bir patolojidir. Literatürde pulmoner kanama gelişen hastalarda \%38-76 arasında değişen oranlarda mortalite bildirilmiştir $(2,4,5)$. Özalkaya ve ark.'nın (11) çalışmasında mortalite \%83,7 olarak saptanmıştır. Özellikle gelişmekte olan ülkelerde pulmoner kanama preterm yenidoğanlarda mortalite için önemli bir risk faktörüdür (19). Güney Afrika'dan bir çalışmada neonatal ölümlerin $\% 12,3$ 'ünde pulmoner kanama bildirilmiş ve bunların \%87'sini 28 32 gestasyon haftasındaki prematüreler oluşturmuştur (20). Bizim çalışmamızda, pulmoner kanama gelişen bebeklerde $\% 90,3$ olarak oldukça yüksek bir mortalite gözlendi.

\section{SONUÇ}

Çalışmamızda ÇDDA'ı preterm bebeklerde ülkemiz ve uluslararası veriye göre daha yüksek sıklıkta pulmoner kanama gözlenmiştir. Doğum ağılığının düşüklüğü, antenatal steroid uygulanmaması ve doğum salonunda entübasyon gereksinimi pulmoner kanama ile ilişkili risk faktörleri olarak saptanmış ve pulmoner kanama postnatal 40. saat gibi erken dönemde gerçekleşmiştir. Bu risk faktörleri ve kanama zamanı patofizyolojide antenatal ve perinatal faktörlerin etkin olabileceğini düşündürmektedir. Pulmoner kanama yenidoğan yoğun bakım uygulamalarındaki gelişmelere rağmen yüksek mortalite ile seyreden bir patolojidir. Bu nedenle, pulmoner kanama gelişimindeki risk faktörlerinin bilinmesi ve önlemeye yönelik çalışmalar önem kazanmaktadır. Antenatal bakımı iyileştirmek pulmoner kanama sıkıı̆ını azaltabilir.

Çıkar çatışması: Bildirilmemiştir.

Yazarlık katkıları: Hipotez geliştirme - Ö.B., E.Y.B.; Tasarım - Ö.B., E.Y.B.; Veri elde etme - E.Y.B., A.I.Z., D.A.; Veri analizi ve yorumlama - Ö.B., A.I.Z., D.A.; Makale yazımı -Ö.B.; Kontrol - E.Y.B., D.A.; Kaynak taraması - A.I.Z., D.A.; Eleştirel inceleme - Ö.B., A.I.Z.

\section{REFERANSLAR}

1. Riad Abou Zahr AA. Mary Marron-Corwin Neonatal pulmonary hemorrhage NeoReviews 2012;13:e302-6.

2. Berger TM, Allred EN, Van Marter LJ. Antecedents of clinically significant pulmonary hemorrhage among newborn infants. J Perinatol 2000;2:295-300. 
3. Yen TA, Wang CC, Hsieh WS, Chou HC, Chen CY, Tsao PN. Short-term Outcome of Pulmonary Hemorrhage in Very-Low-Birth-Weight Preterm Infants. Pediatr Neonatol. 2013;54(5):330-4.

4. Ferreira $\mathrm{CH}$, Carmona F, Martinez FE. Prevalence, Risk Factors and Outcomes Associated with Pulmonary Hemorrhage in Newborns. J Pediatr (Rio J) 2014;90(3):316-22.

5. Pandit PB, O'Brien K, Asztalos E, Colucci E, Dunn MS. Outcome following pulmonary haemorrhage in very low birthweight neonates treated with surfactant. Arch Dis Child Fetal Neonatal Ed 1999;81:F40-4.

6. Tomaszewska M, Stork E, Minich NM, Friedman H, Berlin S, Hack M. Pulmonary Hemorrhage: Clinical Course and Outcomes Among Very Low-Birth-Weight Infants. Arch Pediatr Adolesc Med 1999;153(7):715-21.

7. Garland J, Buck R, Weinberg M. Pulmonary Hemorrhage Risk in Infants With a Clinically Diagnosed Patent Ductus Arteriosus: A Retrospective Cohort Study. Pediatrics 1994;94(5):719-23.

8. Bozkurt O. Causes of death in a neonatal intensive care unit in Southeast region of Turkey. Annals of Medical Research. 2019;26(5):879-83.

9. Parry G, Tucker J, Tarnow-Mordi W, UK Neonatal Staffing Study Collaborative Group. CRIB II: an update of the clinical risk index for babies score. Lancet 2003;361(9371):1789-91.

10. Papile LA, Burstein J, Burstein R, Koffler H. Incidence and evolution of subependymal and intraventricular hemorrhage: a study of infants with birth weights less than 1,500 gm. J Pediatr 1978;92(4):529-34.

11. Özalkaya E, Karatepe HÖ, Topçuoğlu S, Dinçer E, Karatekin G, Ovalı F. Premature yenidoğanlarda pulmoner kanama risk faktörleri. Zeynep Kamil Tıp Bülteni 2015;46(3):116-119.

12. Cole VA, Normand IC, Reynolds EO, Rivers RP. Pathogenesis of hemorrhagic pulmonary edema and massive pulmonary hemorrhage in the newborn. Pediatrics 1973;51(2):175-187.
13. Ren XL, Fu W, Liu J, Liu Y, Xia RM. Lung ultrasonography to diagnose pulmonary hemorrhage of the newborn. J Matern Fetal Neonatal Med 2017;30(21):2601-2606.

14. Chen YY, Wang HP, Lin SM, Chang JT, Hsieh KS, Huang FK, et al; Taiwan Premature Infant Development Collaborative Study Group. Pulmonary Hemorrhage in Very Low-Birthweight Infants: Risk Factors and Management. Pediatr Int 2012;54(6):743-7.

15. Sarno L, Corte LD, Saccone G, Sirico A, Raimondi F, Zullo F, et al. Histological chorioamnionitis and risk of pulmonary complications in preterm births: a systematic review and Meta-analysis. J Matern Fetal Neonatal Med 2019;13:1-10.

16. Kluckow M, Evans N. Ductal shunting, high pulmonary blood flow, and pulmonary hemorrhage. J Pediatr 2000;137(1):68-72.

17. Scholl JE, Yanowitz TD. Pulmonary hemorrhage in very low birth weight infants: a case-control analysis. J Pediatr 2015;166(4):1083-4.

18. Alfaleh K, Smyth JA, Roberts RS, Solimano A, Asztalos EV, Schmidt B, Trial of Indomethacin Prophylaxis in Preterms Investigators. Prevention and 18-month outcomes of serious pulmonary hemorrhage in extremely low birth weight infants: results from the trial of indomethacin prophylaxis in preterms. Pediatrics 2008;121(2):e233-8.

19. Thakur N, Saili A, Kumar A, Kumar V. Predictors of mortality of extremely low birthweight babies in a tertiary care centre of a developing country. Postgrad Med J 2013;89(1058):679-84.

20. Dufourq N, Thomson M, Adhikari M, Moodley J. Massive pulmonary haemorrhage as a cause of death in the neonate--a retrospective review. S Afr Med J 2004;94(4):299-302. 